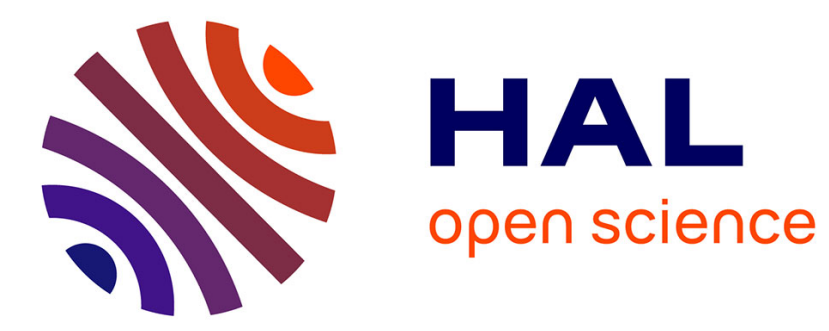

\title{
Woodland bird response to landscape connectivity in an agriculture-dominated landscape: a functional community approach
}

\author{
Assu Gil-Tena, Jean Nabucet, Cendrine Mony, Julie Abadie, S. Saura, Alain \\ Butet, Françoise Burel, Aude Ernoult
}

\section{To cite this version:}

Assu Gil-Tena, Jean Nabucet, Cendrine Mony, Julie Abadie, S. Saura, et al.. Woodland bird response to landscape connectivity in an agriculture-dominated landscape: a functional community approach. Community Ecology, 2014, 15 (2), pp.256 - 268. 10.1556/ComEc.15.2014.2.14 . hal-01090613

\section{HAL Id: hal-01090613}

\section{https://hal-univ-rennes1.archives-ouvertes.fr/hal-01090613}

Submitted on 3 Dec 2014

HAL is a multi-disciplinary open access archive for the deposit and dissemination of scientific research documents, whether they are published or not. The documents may come from teaching and research institutions in France or abroad, or from public or private research centers.
L'archive ouverte pluridisciplinaire HAL, est destinée au dépôt et à la diffusion de documents scientifiques de niveau recherche, publiés ou non, émanant des établissements d'enseignement et de recherche français ou étrangers, des laboratoires publics ou privés. 
4 Woodland bird response to landscape connectivity in an agriculture-dominated landscape: a functional phone: +34 973481752 / fax: +34 973481392

E-mail address: assu.gil@ctfc.cat

23 "Corresponding author. 
28 Keywords: alpha diversity, Brittany, community similarity, CONEFOR, ecological networks,

GRAPHAB, landscape matrix permeability, spatial scale

Over the last 30 years, ecological networks have been deployed to reduce global biodiversity loss by enhancing landscape connectivity. Bird species dwelling in woodland habitats that are embedded in agriculture-dominated landscapes are expected to be particularly sensitive to the loss of connectivity. This study aimed to determine the role of landscape connectivity in woodland bird species richness, abundance, and community similarity in north-east Brittany (north-west France). An exhaustive woodland selection protocol was carried out to minimize the effects of woodland size on the response variables. Connectivity of the woodland and forest network in the study area was evaluated using graph-theory, accounting for matrix permeability, and a characteristic median natal dispersal distance at the community level based on the bird species pool recorded in the sampled woodlands. Information-theoretic model selection, controlling for woodland size in all the cases, depicted the response of woodland birds at the community level to the connectivity of agriculture-dominated landscapes.

On average, the sampled woodlands $(n=25)$ contained $15.5 \pm 2.4$ bird species, with an abundance of 25.1

$44 \pm 3.9$, and had highly similar bird communities (species composition and proportion); eight species represented $57 \%$ of total abundance and were present in at least 22 woodlands. The performance of models improved when using effective, rather than Euclidean, interpatch distances in the connectivity assessment. Landscape connectivity was only significantly related to similarity of proportional species composition. Large woodlands contained communities with more similar species proportions in an inhospitable agricultural landscape matrix than in a more permeable one. Woodland size was the most relevant factor determining species abundance, indicating that the bird population sizes are primarily proportional to the local habitat availability. Connectivity in relation to landscape matrix permeability did not seem to induce the flow of woodland-dependent bird species that are dominant in the community but rather of matrix-dwelling bird species that are less dependent on woodland patch area. In conclusion, both habitat conservation and restoration (i.e., amount and quality), in combination with permeable landscape structures (such as heterogeneous land cover mosaics), are advocated for community level conservation strategies. 


\section{INTRODUCTION}

Land-use change has major impacts on the structure of communities (Sala et al. 2000), and might also influence ecosystem stability (resistance and resilience to environmental changes) (Cleland 2012). Since the 1980s, multi-scale ecological networks have been successfully deployed at the political and societal level, with the aim to reduce the rates of biodiversity declines in human-modified ecosystems (Jongman et al. 2004). Dispersal is recognized as a key ecological process for community composition and diversity (Kadoya 2009), and is largely dependent on landscape connectivity. Landscape connectivity represents the degree to which a given landscape facilitates or impedes the movement of organisms among habitat resources (Taylor et al. 1993). Therefore, the relevance of landscape connectivity for many ecological processes, and for biodiversity conservation, is widely acknowledged (Crooks and Sanjayan 2006, Kindlmann and Burel 2008). Different types of connectors among habitats (e.g., corridors, stepping stones) or the permeability of the landscape will allow the movement, or flow, of organisms, and sustain ecological processes that are fundamental for biodiversity persistence in ecosystems dominated and fragmented by human activities (Bennett et al. 2006). More empirical data are needed to understand the influence of connectivity beyond the population level (Laitila and Moilanen 2013, Muratet et al. 2013). Previous studies have mostly focused on single species, and obtained contradictory results depending on the type of connector or species being considered (Hoyle and Gilbert 2004, Damschen et al. 2006, Baker 2007, Ockinger and Smith 2008). Yet, the outstanding importance of implementing corridors to protect biodiversity is universally agreed upon (Gilbert-Norton et al. 2010). However, species-specific responses to connectivity make difficult the deployment of effective planning schemes aimed at preserving overall biodiversity. Multi-species response to connectivity is rarely considered (but see Gil-Tena et al. 2013, Muratet et al. 2013) and accurate sampling protocols at the suitable scale are needed to obtain reliable data about the response of biological diversity to connectivity (e.g., controlling for other masking effects, such as patch area and edge effects; Smith et al. 2009). The quantification of landscape connectivity represents a major and evolving challenge because landscape characteristics and species dispersal capabilities must be inferred (Taylor et al. 2006), since it is very difficult to measure species dispersal directly (Sutherland et al. 2000). A more permeable landscape matrix is expected to promote dispersal (Baum et al. 2004; Rösch et al. 2013). Landscape elements 
composed of different types of permeable land cover have the potential to enhance connectivity and, ultimately, biodiversity in highly human modified systems (Watts et al. 2010), particularly from a community perspective (Gilbert-Norton et al. 2010). This interpretation advocates for a functional approach of landscape connectivity assessments rather than using connectivity measures that obviate species dispersal capabilities and/or matrix permeability (i.e., structural connectivity; Taylor et al. 2006, Kindlmann and Burel 2008). Hence, new improved connectivity methods have been recently developed that allow landscape connectivity pattern to be analyzed through graph theory indices, as well as from a species-specific (more functional) perspective by considering the dispersal capacity of species (Saura and

94 Pascual-Hortal 2007, Saura and Torné 2009, Saura and Rubio 2010, Foltête et al. 2012). In addition, increasing awareness about the need to account for the capability of species to traverse different types of land covers in landscape connectivity assessment has led to the promotion of related analytical methodologies such as least-cost path modeling (Adriaensen et al. 2003, Rayfield et al. 2010, Gurrutxaga et al. 2011). Without excluding some level of uncertainty in matrix permeability modeling (McRae 2006, Rayfield et al. 2010), these methodological advances, combined with more functional analytical

100 approaches, provide an opportunity to incorporate less biased criteria based on connectivity assessment in 101 ecological network deployment.

102 In agriculture-dominated regions subject to protracted management, such as those in Europe, woodlands

103 and forests represent semi-natural habitats, with a high degree of fragmentation, despite supporting a

104 significant number of animal and plant species. Increasing agricultural intensification since 1960s has

105 favored more open landscapes that are dominated by increasingly larger crop areas, resulting in the

106 further loss of semi-natural habitats and associated components, which has had a consequent negative 107 impact on farmland biodiversity (Benton et al. 2003). Hedgerows are a potential supplementary habitat

108 for some woodland species in agriculture-dominated landscapes (Fuller et al. 2001, Davies and Pullin 109 2007). Yet, as a consequence of agricultural intensification and the associated landscape homogenization 110 over the last century, the length of the hedgerow network surrounding crop fields, which characterizes the 111 countryside of many European regions, has been also decreasing. Hedgerows have a recognized role as 112 corridors for certain species (Haas 1995, Gilbert-Norton et al. 2010); hence, dispersal among woodland 113 patches may be hampered due to reduced landscape matrix permeability among isolated woodlands. 
114 In this study, we analyze the effect of landscape connectivity on bird alpha diversity, abundance and

115 community similarity in the woodlands of the agriculture-dominated landscape of north-east Brittany in

116 north-west France. We specifically assessed connectivity of the woodland and forest network in the study

117 area through graph theory and matrix permeability modeling techniques, because they allowed for a

118 functional landscape connectivity assessment. The role of connectivity may vary with woodland size

119 since the presence of individuals and species in smaller woodlands may be more dependent on landscape

120 connectivity than in larger ones (Rösch et al. 2013). Hence, an exhaustive selection protocol was carried

121 out to minimize the effects of woodland size on the response variables. We explicitly tested factors that

122 were likely to influence the landscape connectivity analysis, and the matrix permeability assessment, such

123 as spatial grain and extent, and interpatch distance type (Euclidean or effective) (Fall et al. 2007, Pascual-

124 Hortal and Saura 2007, Moilanen 2011). In addition, we also tested whether matrix permeability

125 improved the modeling of bird alpha diversity, abundance, and bird community similarity. We expect a

126 positive response of woodland bird community to landscape connectivity, with richer and more similar

127 communities in more permeable landscapes, without ruling out the likely interaction with woodland size.

\section{MATERIALS AND METHODS}

130 Study area

131 The study area encompassed the Armorique Zone Atelier (Armorique ZA; ca., 13000 ha), which is

132 located in NE Brittany, and is integrated in the LTER (Long Term Ecological Research) international

133 network. Brittany is part of the Armorican Massif, which is composed of shale and granite bedrock, with

134 loess deposits on the northern coast. The climate is oceanic, and the landscape is dominated by agriculture

135 (with forested areas covering just 12\% of the region), and is strongly influenced by intensive farming

136 devoted to dairy cows, pigs, and poultry. The Armorique ZA is mainly a set of countryside agrosystems

137 that have an extensive hedgerow network, a marshy region to the east in the Couesnon Valley, and the

138 Villecartier forest to the south (Fig. 1). The typical landscape structure (or bocage) shows an increasing

139 density gradient from north to south, with a denser hedgerow network in the southern Armorique ZA. 


\section{Woodland selection and conceptual landscape model adopted}

144 The initial land-use map that was used to determine which woodlands would be sampled in the

145 Armorique ZA was obtained from a photointerpretation of aerial photography (French National Institute

146 of Geographic and Forest Information) in combination with object based and remote sensing aerial

147 classification by Rapideye satellite data collected during 2010. Six land-use categories were identified:

148 crops, seminatural grasslands, managed grasslands, woodlands and forests, urban areas (e.g., villages),

149 and water bodies. Moors and heathlands were not mapped because they are very rare in the region. The

150 hedgerow network and roads were identified from the vector geographic database BDTopo® $(2003-$

151 2006), which was produced by the French National Institute of Geographic and Forest Information.

152 To select woodlands for sampling, all woodlands that were separated by less than $25 \mathrm{~m}$ from the edges

153 were first grouped as a single unique woodland area. As a result, 143 woodland and forest habitats

154 (woodlands smaller than forests) were identified in the Armorique ZA. The average forest patch size is 2

155 ha. To minimize the size and edge effects on the response variables characterizing bird community,

156 homogeneous woodland sample selection was conducted [woodland size ranged from 1 ha to 8 ha, with

157 woodland compactness [perimeter $(\mathrm{m}) / \mathrm{size}\left(\mathrm{m}^{2}\right)$ ] being set below the median (i.e., 0.04)]. Twenty-five

158 woodlands (Fig. 1) were selected based on their naturalness and forest management homogeneity, which

159 was confirmed through preliminary winter fieldwork. Habitat descriptors of the 25 selected woodlands

160 were recorded, including descriptions of their age, canopy cover, and tree species richness. Woodland age

161 was determined from ancient land cover maps (1862) and orthophotography in 1952, 1974, 1985, 1996,

162 and 2004. We measured canopy cover and tree species richness in six $14 \times 5 \mathrm{~m}$ squares placed in the core

163 (3) and edges (3) of each woodland. Woodland core was defined as the central area $25 \mathrm{~m}$ from the edge

164 (trees with diameter at the breast height greater than $10 \mathrm{~cm}$ ). It was not possible to consider other habitat

165 descriptors linked to forest management in the woodlands after telephone interviews with the owners,

166 because of lack of data precision (all of the sampled woodlands were private, and managed to obtain

167 firewood).

168 According to Fischer and Lindenmayer (2006) different conceptual landscape models can be applied to

169 explain wildlife distributions (e.g., the fragmentation and the continuum model). The conceptual

170 landscape model adopted for studying the bird community dwelling in woodlands of the agriculture-

171 dominated landscape in NE Brittany was the fragmentation model. The fragmentation model assumes 
172 that: (1) there is a clear contrast between the human-defined habitat patches (woodlands) and areas

173 outside the patches (agricultural landscape matrix); (2) the considered species within the woodland bird

174 communities have similar habitat requirements (e.g., species nesting in woodlands); and (3) the landscape

175 pattern is a good indicator of multiple interacting processes and for this reason we tested the role of

176 landscape connectivity on bird community response.

178 Bird data collection

179 Bird species occurrence and abundance were estimated in each woodland using the point-count method

180 (Bibby et al 1992, Ralph et al 1993). This method is similar to the North American Breeding Bird Survey

181 and the British Constant Effort Sites Scheme (Sauer et al. 1997, Peach et al. 1998). A 5-min point count

182 was conducted in the morning by the same observer (R.M.) approximately at the center of each woodland,

183 under calm weather conditions, and all individual bird species that were seen or heard within a 100-m

184 fixed radius were recorded. A hundred meter radius corresponds to the maximum distance where the

185 greater bird species may be contacted in forest (Bibby et al., 1992), most species being detected in a circle

186 of 50 meters centered on the counting point. Despite considering the most compact woodlands, variations

187 in shape irregularity and size (1-8 ha) of the 25 selected woodland patches made distance from point

188 count centers to woodland edges was about $75 \mathrm{~m}$. When necessary, point count boundaries were

189 established in order to record only birds inside woodlands (i.e., excluding open-country birds). Therefore,

190 we assume that our protocol did not induce an excessive edge effect bias to estimate abundance and the

191 compositional indices of the woodland bird communities from the smallest to the largest patches because

192 woodland core and edges were well covered by the point count surface in all the cases, and particularly

193 considering that woodlands were visited 3 times during the breeding season (April, May and June).

194 The species that were selected for analysis in this study were those that were characteristic of the

195 woodlands in the region. Consequently, we excluded Pica pica, Columba oenas, and raptors (Buteo

196 buteo) from the analysis. Pica pica is a farmland species rarely nesting inside woodlands, and Columba

197 oenas is extremely rare in wood patches of our study area, recording only one case of presence without

198 certainty of nesting. We remove Buteo buteo from data as its detection was more random than most of the

199 singing passerine species and because the species often leaves wood patches at observers' arrival. 
200 For the sampled woodlands, we calculated: bird species richness and the total species maximum

201 abundance across three visits during the breeding season. For each species in the sampled woodlands,

202 maximum abundance (hereafter termed abundance) was computed from the number of visual and sound

203 contacts with a species during each point count.

Similarity measures of the woodland bird community

206 We computed two different measures of community similarity. The first measure is based on traditional measures of spatial turnover, which are derived from three matching/mismatching components: continuity (the total number of species shared by two areas), gain (the number of species present in an area but absent from the focal area), and loss (the number of species present in the focal area but absent from the other area) (Gaston et al. 2007). For this study, we used the modified Simpson's index of beta diversity [a

211 dissimilarity measure, $D(S=1-D)$ ], which quantifies the relative magnitude of the gains and losses of a

212 given species [min(gain, loss)/(min(gain, loss) + continuity)] (Lennon et al. 2001). This measure allowed

213 us to determine the true differences in species composition among sites (hereafter termed composition

214 similarity), separating the influence on species composition due to local richness gradients (i.e.,

215 nestedness).

216 The other measure of similarity indicated the overlap among sampled woodlands in terms of proportional

217 species composition (hereafter termed proportional similarity). The Morisita-Horn similarity index was

218 computed because of its robustness against species richness, although it is highly sensitive to the

219 abundance of the most abundant species (Wolda 1981, Magurran 2009). The index is presented as:

220 Proportional similarity $=2 \Sigma\left(a n_{i} * b n_{i}\right) /\left[(d a+d b)^{*}\left(N a^{*} N b\right)\right]$,

221 where $N a$ and $N b$ are the total number of individuals in site $A$ and $B$, respectively, $a n_{i}$ and $b n_{i}$ are the total 222 number of individuals of $i$ th species in site $A$ and $B$, respectively, and $d a$ and $d b$ are $\Sigma a n_{i}{ }^{2} / N a^{2}$ and $\Sigma b n_{i}^{2}$ $223 / N b^{2}$, respectively.

224 Both similarity measures were computed from the corresponding dissimilarity matrices by the "vegan"

225 package (Oksanen et al. 2013) in $R$ (http://www.r-project.org). For each sampled woodland, we averaged 226 the similarity values in comparison to the remaining sampled woodlands in the study area. 


\section{Landscape connectivity assessment}

230 From the land-use map and the hedgerow and road network, the landscape connectivity of the sampled

231 woodlands was computed by graph theory using Conefor 2.6 (Saura and Torné 2009;

232 http://www.conefor.org). Our connectivity measure for a given woodland patch $k\left(d F^{*}{ }_{k}\right)$ assessed the

233 percentage of total dispersal flux among all woodland and forest patches in the landscape that occurs

234 through the connections of patch $k$ with all other patches in the landscape (when $k$ is either the starting or

235 ending patch of that connection or flux). $d F^{*}$ is given by:

236

$$
d F_{k}^{*}=\frac{\sum_{i=1, i \neq k}^{n-1} p_{i k}^{*}}{\sum_{i=1}^{n} \sum_{j=1, i \neq j}^{n} p_{i j}^{*}},
$$

237 where $p^{*}$ ij is the maximum product probability of all possible paths between two patches, $i$ and $j$, in the

238 landscape, including direct and non-direct (facilitated by other intermediate patches functioning as

239 stepping stones) dispersal between the two patches (Saura and Pascual-Hortal 2007).

240 The direct dispersal probabilities $p_{i j}$ between habitat patches were computed by a negative exponential

241 function of interpatch distance, which has been used in many published studies (Bunn et al. 2000, Urban

242 and Keitt 2001, Saura and Pascual-Hortal 2007, Gurrutxaga et al. 2011). The interpatch distance was

243 calculated as the Euclidean and effective distance between all woodland and forest patches in the study

244 area. The decay rate of this negative exponential function was determined by the value of the median

245 natal dispersal distance characteristic of the bird community recorded during the sampling period in the

246 woodlands of the study area (Fig. 2), corresponding to $p_{i j}=0.5$.

247 For these species, the geometric mean natal dispersal distances were extracted from the bird ringing data

248 of the British Trust of Ornithology (Paradis et al. 1998). Data from Paradis et al. (1998) were available for

$24967 \%$ of the recorded bird species, and the median natal dispersal distance characteristic of the bird

250 community in the woodlands of the study area was $1.3 \mathrm{~km}$.

251 The Euclidean and effective (considering landscape matrix permeability) distances between each pair of

252 habitat patches (including both sampled and unsampled woodlands and forests within the study area)

253 were calculated with Graphab 1.0 software (Foltête et al. 2012; http://thema.univ-

254 fcomte.fr/productions/graphab/). The effective distances between each pair of woodlands or forests 
(including sampled and unsampled habitats) were calculated as the accumulated cost along the least cost paths throughout friction surfaces (Adriaensen et al. 2003) (see Table 1). Although birds fly and are less sensitive to matrix permeability, in the connectivity assessment we specifically considered the matrix impedance of this agriculture-dominated landscape. Permeable landscape structures may encompass different types of landscape elements, such as stepping stones or heterogeneous land cover mosaics, which are more permeable for species movements (Baum et al. 2004, Rösch et al. 2013). Uncertainty is usually associated with the friction values for different land cover types (Rayfield et al. 2010); however, the friction values and habitat classification of this study were based on Watts et al. (2010), according to

263 the degree of ecological modification of the vertical structure of different land cover types that might

264 affect birds in woodlands. The study by Watts et al. (2010) was conducted in a similar agricultural context

265 in the UK. In our case, the friction values correspond to a mathematical exponential function, with a maximum friction threshold of 50, which were very similar to those of Watts et al. (2010) based on expert criteria. Like Gurrutxaga et al. (2011), the characteristic median natal dispersal distance of the sampled bird community in the study area was multiplied by the statistical median value of resistance in the

269 friction surface (Table 1). The result indicated the effective distance (accumulated cost) threshold corresponding to a 0.5 dispersal probability between nodes $\left(p_{i j}\right)$ (Saura and Pascual-Hortal 2007).

271 The type of graph that is used might influence the computation of the connectivity metrics, and the understanding of the identified connectivity network (Fall et al. 2007), particularly when considering

273 large spatial extents, fine spatial grains, and a large set of habitat patches or nodes. For instance, a complete graph, with paths between every pair of patches, provides a good ecological representation;

275 however, it poses challenges for computational processing and visualization, particularly for planning 276 purposes. In comparison, the minimum planar graph (Fall et al. 2007) is a spatial generalization of

277 Delaunay triangulation in which only neighboring patches can be linked, and provides a reasonable 278 approximation of the complete graph, while facilitating the visualization and comprehension of the 279 connectivity network. In this study, we tested whether the use of a complete graph versus a minimum 280 planar graph affects the modeling performance of community bird diversity, and abundance. For this 281 purpose, we used Graphab 1.0, which allows different types of graph architectures to be computed. 
graph), because it considers maximum product probabilities (direct and non-direct dispersal between two patches).

285 The effects of scale issues, such as spatial grain and extent, on the connectivity analysis are rarely considered in studies that rank landscape elements by their contribution to overall landscape connectivity

287 (but see Pascual-Hortal and Saura 2007, Gil-Tena et al. 2013). In this study, spatial grain and extent was constrained by computational limitations. The finest spatial grain that was used to compute landscape connectivity was $2 \mathrm{~m}$, which forced us to consider a maximum spatial extent of $3 \mathrm{~km}$ around the Armorique ZA (355 woodlands and forests; Fig. 1). In comparison, at a spatial grain of $10 \mathrm{~m}$, the spatial extent considered was $5 \mathrm{~km}$ (429 woodlands and forests; Fig 1). Considering a larger spatial extent than the target one (e.g., Armorique ZA in this study) has been suggested as adequate when computing graph-

293 based connectivity measures such as $d F^{*}$ which do not take into account patch area (Pascual-Hortal and

294 Saura 2007). The land-use map showing the different extents was obtained in the same manner as for the

295 Armorique ZA extent, using the same aerial photography and satellite imagery.

296 Figure 3 provides a schematic representation of the various factors that were considered in the

297 connectivity assessment using graph theory, in addition to the corresponding abbreviations of the nomenclature [also see the summary statistics of the connectivity values of the sampled woodlands $(n=$

$29925)$ in Table 2].

300

\section{Data analysis}

302 Ordinary Least Squares (OLS) regression was used to model bird species richness, species abundance,

303 and the similarity in species composition (composition similarity) and in proportional species composition (proportional similarity) as a function of landscape connectivity. In all regression analyses, woodland characteristics (age, averaged canopy cover, and tree species richness) were also considered, and woodland size was always retained in the model due to differences in the size of the sampled woodlands (Table 2). In addition, the interaction between landscape connectivity and woodland size was tested in order to check if woodland bird community response to landscape connectivity depends on

309 woodland size. A backward step-wise OLS model selection was performed to adjust the final OLS model.

310 We checked the variance inflation factors in the OLS models, which were always under 1.4, indicating 311 the absence of strong linear dependencies among the independent variables. To compare alternative $a$ 
312 priori models, we used the information-theoretic model comparison approach based on second-order

313 Akaike's Information Criterion corrected for small sample sizes (AICc) (Burnham and Anderson 2002).

314 All the statistical analyses were performed with the "MASS" package (Venables and Ripley 2002) in $R$.

315 Spatial autocorrelation in the response variables and model residuals was checked through Moran's $I$ by

316 means of the "ape" package in $R$ (Paradis et al. 2004).

\section{RESULTS}

319 In the 25 sampled woodlands, 30 bird species were recorded. On average, the sampled woodlands

320 contained 15.48 bird species, with a mean abundance of 25.1 (Table 2). The bird species assemblages of

321 the sampled woodlands also had highly similar species composition and proportional species composition

322 (average values of 0.86 and 0.88, respectively) (Table 2). Eight bird species were found in almost all the

323 sampled woodlands (Phylloscopus collybita, Fringilla coelebs, Troglodytes troglodytes, Sylvia

324 atricapilla, Columba palumbus, Erithacus rubecula, Turdus merula, and Cyanistes caeruleus were

325 present in at least 22 woodlands) and had a relative maximum abundance greater than $5 \%(5-11 \%, 57 \%$ in

326 total), whereas the remaining 22 species were less frequent and abundant (10 species with less than 1\%

327 relative maximum abundance) (Fig. 2). Spatial autocorrelation in the bird community response variables

328 was not significant $(\mathrm{p}>0.05$, results not show).

329 Greater variability was obtained in the patch-level connectivity metric that did not take matrix resistance

330 into account compared to that using the effective distances among woodlands and forests of the

331 Armorique ZA (Fig. 4). This result was consistent across the two spatial extents that were considered (3

332 and $5 \mathrm{~km}$ ). Connectivity values tended to be greater for the smallest spatial extent (i.e., $3 \mathrm{~km}$ ). Similar

333 patterns were observed in the sampled woodlands $(n=25$; Table 2$)$. For the sampled woodlands, we

334 recorded similar connectivity measurements depending on the type of spatial resolution (2 and $10 \mathrm{~m})$ and

335 the type of graph (complete graph and minimum planar graph) (Wilcoxon test, $p>0.05$ ). However, we

336 demonstrated that spatial extent and the type of interpatch distance (Euclidean or effective) had a

337 significant effect (Wilcoxon test, $p \leq 0.05$; results not shown).

338 The models of species richness and composition similarity were not significant $(p>0.05)$, whereas the

339 models of proportional similarity and abundance were significant. The modeling of proportional

340 similarity improved when the permeability of the agricultural matrix was taken into account in the 
341 connectivity assessment, because all of the best regression models according to AICc were those that

342 considered effective distances, rather than Euclidean distances (Table 3). In the best regression models

$343(\Delta \mathrm{AICc} \leq 2)$ for similarity in the proportion of bird species composition (proportional similarity), about

$34420 \%$ of the variability was explained (adjusted- $R^{2}$, Table 3 ). These models indicated that woodland size

345 and connectivity accounting for matrix permeability had a similar influence on proportional similarity;

346 woodland size positively influenced proportional similarity, whereas connectivity negatively influenced

347 proportional similarity (Table 3). According to the best regression model $(\triangle \mathrm{AICc}=0)$, when woodland

348 size remained constant, one unit increment in connectivity $(\mathrm{CEf} 2 \mathrm{~m} 3 \mathrm{~km})$ decreased proportional similarity

349 by 0.29 units, whereas 1 ha woodland increased proportional similarity by 0.007 units (Fig. 5). The model

350 predicting species abundance had a determination coefficient of $0.18(p=0.02)$, and showed that bird

351 abundance was only positively associated with woodland size $(p=0.02)$ (Table 3$)$. Bird abundance nearly

352 increased by 1 unit (0.987) with each 1 ha increment in woodland size. In any case, the interaction

353 between landscape connectivity and woodland size nor spatial autocorrelation in model residuals were

354 significant $(\mathrm{p}>0.05$, results not show).

355

\section{DISCUSSION}

357 This study confirmed the relevance of using effective distances (i.e., considering the landscape matrix

358 heterogeneity) for graph-based connectivity assessments aimed at explaining woodland bird community

359 composition in an agriculture-dominated landscape. The agricultural matrix of the study area was

360 dominated by crops and grasslands (Fig. 1); thus, more reliable measures were obtained when taking

361 matrix permeability into account. We hypothesize that this result would be even more prominent for non-

362 flying species, such as mammals, as previously shown at the species and population level (Gurrutxaga et

363 al. 2011, Carranza et al. 2012, Decout et al. 2012), as well as for plants at the community level (Muratet

364 et al. 2013).

365 Results did not support our main hypothesis, regarding the positive effect of connectivity on the response

366 variables. The relatively small sample size $(n=25)$ might have influenced model significance (e.g.,

367 species richness and composition similarity). The alternative best models for species richness using the

368 AICc approach were marginally significant (model $p$-value $\leq 0.1$, with an adjusted- $R^{2}$ about of 0.16 ), and

369 were not always conclusive regarding the positive effect of landscape connectivity (results not shown). In 
370 revegetated urban patches in Australia, connectivity was shown to be the main factor explaining bird

371 species richness, because more colonizers were able to reach more available habitat area (Shanahan et al.

372 2011). In agriculture-dominated landscapes, the disruption of matrix-dwelling species (e.g., species less

373 dependent on woodland patch area to breed) cannot be excluded (Fuller et al. 2001, Ewers and Didham

374 2006), and might, ultimately, increase species richness in woodlands. The lack of model adjustment for

375 the similarity of species composition might be related to the fact that bird communities in small

376 woodlands might be similar to those of hedgerows (Fuller et al. 2001). In the Armorique ZA, hedgerow

377 density increases from north to south, ranging from approximately 44 to $115 \mathrm{~m} / \mathrm{ha}$, respectively, with a

378 total length of $575 \mathrm{~km}$ (Vannier 2012). This spatial heterogeneity in hedgerow density might prevent

379 direct responses in composition similarity from being determined. In this study, we only controlled for the

380 effect of woodland size (e.g., on species richness), because the influence of hedgerows was considered in

381 the connectivity assessment when accounting for matrix permeability. In the specific case of composition

382 similarity, a control for the influence of the hedgerow network would be preferred, but is not feasible at

383 the extent of the current analysis, if woodland size is also considered. In addition, the assumptions taken

384 when we selected the fragmentation model as landscape conceptual model may affect the obtained lack of

385 landscape connectivity importance (Price et al. 2009). On the one hand, it is possible that the community-

386 level approach might have masked some relationships, due to differences in the recorded species

387 ecological traits (Ewers and Didham 2006, Batáry et al. 2012). On the other hand, averaged canopy cover

388 of the selected woodlands finally ranged from $38 \%$ to $91 \%$ (with Q2 $=68 \%$ and IQR $=20$ ). This may

389 affect woodland bird community composition, particularly the species more associated with more open

390 canopy covers which are more sensitive to canopy closure (e.g. Phyllocopus trochilus, Sylvia borin,

391 Prunella modularis; Hinsley et al. 2009), although canopy cover was not significant in any computed

392 model.

393 Our most outstanding result was the negative effect of connectivity on the similarity of proportional

394 species composition, which was only obtained when considering landscape matrix heterogeneity. This

395 negative influence of connectivity on proportional species composition, together with the positive

396 association with woodland size, might indicate that large woodlands contain more similar bird

397 communities in an inhospitable matrix compared to those in a more permeable agricultural landscape

398 matrix. Although the effect of landscape connectivity may be modulated by the amount of habitat (Rösch 
et al. 2013), in this study the interaction between landscape connectivity and woodland size was not significant. This result may be partially due to the low size range of the selected woodlands and the focus on the smallest woodlands. Less dominant woodland bird species in the community (see Fig. 2) but highly dependent on landscape connectivity due to their sensitivity to woodland fragmentation in agriculture-dominated landscapes [e.g., Sitta europaea (Verboom et al. 1991)] or other specialists such as Regulus ignicapilla less dependent on woodland size (Tellería and Santos 1995), may contribute to community dissimilarity in permeable landscapes. Enhanced agricultural landscape matrix permeability might also produce an overlap between woodland bird species and matrix-dwelling species (Cook et al. 2002), which ultimately produces different proportions in the species composition of bird species that are typical of woodlands in the study area. Moreover, competition processes with species that have wider habitat breadths must be considered, as this phenomenon might also contribute to increase community dissimilarity. Competition and interactions with other species might be different at habitat edges compared to the interior, although the landscape context might buffer interspecific relationships (Ewers and Didham 2006). Therefore, we hypothesize that bird species that are less dependent on woodlands in

413 agriculture-dominated landscapes are above all positively influenced by matrix permeability (Fuller et al. 414 2001, Batáry et al. 2012).

415 Assuming that edge effect biases on bird counts were negligible because woodland core and edges were

416 fairly covered by the point count surface in all the cases (see details in the Bird data collection subsection

417 in Material and Methods), woodland size was the only variable positively correlated with species

418 abundance. This significant positive association supports the findings of Shanahan et al. (2011), who

419 found that greater patch area, as well as connectivity, caused bird abundance to increase by expanding the 420 habitat available to species that were already established in revegetated urban patches. In agriculture-

421 dominated landscapes, small woodlands tend to have greater extents of edges, which might ultimately 422 cause greater reproductive failure, due to increased exposure to potential nest predation (Ludwig et al. 423 2012); thus, negatively influencing bird abundance. The lack of association between landscape 424 connectivity and bird abundance when using matrix permeability also suggests that a more permeable 425 matrix does not moderate the edge effects on woodland species. This finding contradicts with previous 426 literature (see Ewers and Didham 2006), but might indicate that abundant woodland bird species in the 427 community are more sensitive to woodland size in agriculture-dominated landscapes compared to 
agricultural landscape matrix permeability. For instance, Batáry et al. (2012) found that woodland bird species are more abundant at the forest edges, but are less abundant in hedges, while the inverse association was obtained for farmland birds.

431 Landscape connectivity influences the immigration and emigration of species, but does not affect other 432 mechanisms that influence population dynamics, such as births and deaths, which are related to habitat availability or quality (Moilanen 2011). If woodland size is the main predictor of bird abundance in

434 woodlands in agriculture-dominated landscapes, with connectivity appearing to be more related to the

435 flow of less dominant or dependent bird woodland species, then rescue effects modulated by immigration

436 might be hampered for bird species that are more dependent on woodlands in small and isolated

437 woodlands. Therefore, more insights are needed into the role of landscape permeability to promote

438 population viability according to species ecological traits (Davies and Pullin 2007). In addition, most of

439 the measures favoring woodland bird species will not equally affect farmland birds, which are indeed

440 more threatened than woodland birds, with significant declining population trends (Gregory et al. 2005)

441 because of agricultural intensification (Donald et al. 2001). Whereas some specialist farmland birds need

442 large extensions of open-habitat characterized by low intensity crop systems (Filippi-Codaccioni et al.

443 2010, Fischer et al. 2011), other farmland birds use woodlands as complementary habitats (Fuller et al.

444 2004). Particularly in the latter case, negative environmental changes affecting woodland birds will also

445 negatively impact on farmland bird communities, such as the hedgerow removal, and the implementation

446 of highly demanding crops with large patch size (e.g., maize; Houet et al. 2010) in the characteristic

447 bocage landscape structure of the study area. New improved graph-based connectivity indices might help

448 integrate and identify the different ways in which landscape elements contribute to habitat availability and 449 connectivity (i.e., inter- and intrapatch connectivity; Saura and Rubio 2010). Results for different types of

450 species with contrasted habitat requirements (e.g., woodland and farmland birds in agricultural

451 landscapes) may be incorporated into decision support tools for landscape planning purposes. Apart from

452 considering the immigration and emigration component of habitat use, these connectivity metrics also

453 take into account the value of local resources in each patch to determine the effective amount of habitat

454 that may be reached by a given species, with both aspects being integrated in a single analytical

455 framework (Saura and Rubio 2010). Nevertheless, the sampling methodology used to monitor bird

456 species dwelling in woodlands prevented us from being able to simultaneously consider other factors that 
also affect the mechanisms involved in population viability because relatively small woodlands were sampled compared to the rest of the study area.

459 Our results also showed that computing connectivity through maximum probability indices, such as $d F^{*}$,

460 could be accelerated by using minimum planar graphs (Fall et al. 2007). For the sampled woodlands, the

461 different spatial extents in the connectivity assessment did not affect the modeling of the response variables. This finding might be partly due to a much larger extent than the study area being taken into account from the onset of the connectivity assessment, as recommended by Pascual-Hortal and Saura (2007). In any case, the spatial grain, which largely reduces the computational times required for connectivity assessments, had an effect with respect to the modelling approach and the magnitude of connectivity among the woodlands and forests in the study area (but see Pascual-Hortal and Saura 2007).

\section{Conclusions}

Identifying how landscape connectivity affects wildlife communities is a major concern, particularly with respect to global change, requiring the development of research strategies that obtain robust inferences. In this study, we demonstrated that connectivity assessment through graph-based methodologies that allow

472 the ecological traits of species to be taken into account (e.g., habitat preferences and dispersal capacities)

473 might represent a relatively unbiased technique for the deployment of ecological networks. These

474 analytical advances are fundamental for the establishment of effective permeable landscape structures 475 aimed at enhancing dispersal. The existing landscape matrix is fundamental for holistically preserving the 476 biodiversity (e.g., at the community level) of agriculture-dominated landscapes. A combination of 477 different landscape conceptual models beyond discrete habitat patches within a less inhabitable matrix 478 might help optimize the community level approach (Price et al. 2009). In addition, new solutions have 479 been recently developed for approximating multi-species community level dispersal (Laitila and

480 Moilanen 2013). However, viable populations depend on both processes influenced by landscape 481 connectivity (emigration and immigration) and habitat availability and quality (births and deaths).

482 Therefore, these factors must also be incorporated into the analyses of management plans for the 483 deployment (design and identification) of ecological networks, and particularly for specialist habitat 484 species, for which landscape matrix permeability does not necessarily enhance the flow of individuals. 485 For this purpose, new improved connectivity measures that are based on a combination of graph theory 
and the habitat availability concept (Saura and Rubio 2010) should be particularly adequate as integrative analytical tools that operationally consider as many different factors as possible that influence population viability.

489

\section{ACKNOWLEDGEMENTS}

Thanks to Regis Morel (Bretagne Vivante) who has carried out the bird censuses and Doriane Moisan who helped in woodland inventories. We also want to thank two anonymous reviewers and Péter Batáry for improving a previous version of this manuscript. This work has received a financial support from the project DIVA 3 - AGRICONNECT (Continuités écologiques dans les paysages agricoles) funded by the Ministère de l'Ecologie et du Développement Durable (France). This work was also framed within the DECOFOR (AGL2009-07140) project (Spanish Government and the European fund for regional development). Rapideye imagery was furnished by GEOSUD. A. Gil-Tena was funded by the Ministerio de Educación (Programa Nacional de Movilidad de RRHH, Plan Nacional de I+D+i 2008-2011, Spain).

499

500

\section{REFERENCES}

501

Adriaensen F., J.P. Chardon, G. De Blust, E. Swinnen, S. Villalba, H. Gulinck and E. Matthysen. 2003.

502 The application of 'least-cost' modelling as a functional landscape model. Landscape Urban Plan. 64: 233-247.

504

505

Baker, L. 2007. Effect of corridors on the movement behavior of the jumping spider Phidippus princeps (Araneae, Salticidae). Can. J. Zool. 85: 802-808.

507

508 Batáry, P., A. Kovács-Hostyánszki, C. Fischer, T. Tscharntke and A. Holzschuh. 2012. Contrasting effect of isolation of hedges from forests on farmland vs. woodland birds. Community Ecol. 13(2): 155-161.

510

511 Baum, K.A., K.J. Haynes, F.P. Dillemuth and J.T. Cronin. 2004. The matrix enhances the effectiveness of 512 corridors and stepping stones. Ecology 85(10): 2671-2676. 
514 Bennett, A., K.R. Crooks and M. Sanjayan. 2006. The future of connectivity conservation. In: K.R.

515 Crooks and M. Sanjayan (eds.), Connectivity Conservation. Cambridge Univ. Press, New York. pp. 676-

516694.

517

518 Benton, T.G., J.A. Vickery and J.D. Wilson. 2003. Farmland biodiversity: is habitat heterogeneity the

519 key? Trends Ecol. Evol. 18: 182-188.

520

521

Bibby, C.J., N.D. Burgess and D.A. Hill. 1992. Bird Census Techniques. Cambridge Univ. Press,

522 Cambridge.

523

524 Bunn, A.G., D.L. Urban and T.H. Keitt. 2000. Landscape connectivity: A conservation application of graph theory. J. Environ. Manage. 59: 265-278.

526

527

Burnham, K.P. and D.R. Anderson. 2002. Model selection and multimodel inference: a practical information-theoretical approach. Springer-Verlag, New York.

529

530 Carranza, M.L., E. D'Alessandro, S. Saura and A. Loy. 2012. Connectivity providers for semi-aquatic 531 vertebrates: the case of the endangered otter in Italy. Landscape Ecol. 27: 281-290.

532

533 Cleland, E.E. 2012. Biodiversity and ecosystem stability. Nat. Educ. Knowl. 3(10): 14.

534

535 Cook, W.M., K.T. Lane, B.L. Foster and R.D. Holt. 2002. Island theory, matrix effects and species

536 richness patterns in habitat fragments. Ecol. Lett. 5: 619-623.

537

538 Crooks K.R. and M. Sanjayan (eds.). 2006. Connectivity conservation. Cambridge Univ. Press, New 539 York.

540

541 Damschen, E.I., N.M. Haddad, J.L. Orrock, J.J. Tewksbury and D.J. Levey. 2006. Corridors increase 542 plant species richness at large scales. Science 313: 1284-1286. 
544 Davies, Z.G. and A.S. Pullin. 2007. Are hedgerows effective corridors between fragments of woodland

545 habitat? An evidence-based approach. Landscape Ecol. 22: 333-351.

Decout, S., S. Manel, C. Miaud and S. Luque. 2012. Integrative approach for landscape-based graph landscapes. Landscape Ecol. 27: 267-279.

550

Donald, P.F., R.E. Green and M.F. Heath, M.F. 2001. Agricultural intensification and the collapse of

Europe's farmland bird populations. P. Roy. Soc. B-Biol. Sci. 268: 25-29.

553

554

Ewers, R.M. and R.K. Didham. 2006. Confounding factors in the detection of species responses to habitat fragmentation. Biol. Rev. 81: 117-142.

556

557

Fall, A., M.J. Fortin, M. Manseau and D. O’Brien. 2007. Spatial graphs: Principles and applications for habitat connectivity. Ecosystems 10: 448-461.

559

560

Filippi-Codaccioni, O., V. Devictor, Y. Bas, J. Clobert and R. Julliard. 2010. Specialist response to

561 proportion of arable land and pesticide input in agricultural landscapes. Biol. Conserv. 143: 883-890.

562

563 Fischer, C., A. Flohre, L.W. Clement, P. Batáry, W.W. Weisser, T. Tscharntke and C. Thies. 2011. Mixed

564 effects of landscape structure and farming practice on bird diversity. Agric. Ecosyst. Environ. 141: 119-

565125.

566

567 Fischer, J. and D.B. Lindenmayer. 2006. Beyond fragmentation: the continuum model for fauna research

568 and conservation in human-modified landscapes. Oikos 112: 473-480.

569

570 Foltête, J.C., C. Clauzel and G. Vuidel. 2012. A software tool dedicated to the modelling of landscape

571 networks. Environ. Modell. Softw. 38: 316-327. 
Fuller, R.J., D.E. Chamberlain, N.H.K. Burton and S.J. Gough. 2001. Distributions of birds in lowland

574 agricultural landscapes of England and Wales: How distinctive are bird communities of hedgerows and woodland? Agric. Ecosyst. Environ. 84: 79-92.

576

Fuller, R.J., S.A. Hinsley and R.D. Swetnam. 2004. The relevance of non-farmland habitats, uncropped areas and habitat diversity to the conservation of farmland birds. Ibis 146: 22-31.

579

580

Gaston, K.J., R.G. Davies, C.D.L. Orme, V.A. Olson, G.H. Thomas, T.S. Ding, P.C. Rasmussen, J.J. Lennon, P.M. Bennett, I.P.F. Owens and T.M. Blackburn. 2007. Spatial turnover in the global avifauna. Proc. R. Soc. Biol. Sci. 274: 1567-1574.

583

584 Gil-Tena, A., R. Lecerf and A. Ernoult. 2013. Disentangling community assemblages to depict an

585 indicator of biological connectivity: A regional study of fragmented semi-natural grasslands. Ecol. Indic. 24: $48-55$.

587

588

Gilbert-Norton, L., R. Wilson, J. R. Stevens and K.H. Beard. 2010. A meta-analytic review of corridor effectiveness. Conserv. Biol. 24: 660-668.

590

591

Gregory, R.D., A. van Strien, P. Vorisek, A.W.G. Meyling, D.G. Noble, R.P.B. Foppen and D.W.

592 Gibbons. 2005. Developing indicators for European birds. Philos. T. R. Soc. B. 360: 269-288.

593

594 Gurrutxaga, M., L. Rubio and S. Saura. 2011. Key connectors in protected forest area networks and the

595 impact of highways: A transnational case study from the Cantabrian Range to the Western Alps (SW

596 Europe). Landscape Urban Plan. 101: 310-320.

597

598 Haas, C.A. 1995. Dispersal and use of corridors by birds in wooded patches on an agricultural landscape.

599 Conserv. Biol. 9: 845-854.

600 
601 Hinsley, S.A., R.A. Hill, R.J. Fuller, P.E. Bellamy and P. Rothery. 2009. Bird species distributions across woodland canopy structure gradients. Community Ecol. 10: 99-110.

603

604

Houet, T., T.R. Loveland, L. Hubert-Moy, C. Gaucherel, D. Napton, C.A. Barnes and K. Sayler. 2010.

Exploring subtle land use and land cover changes: a framework for future landscape studies. Landscape

606 Ecol. 25: 249-266.

607

608

Hoyle, M. and F.S. Gilbert. 2004. Species richness of moss landscapes unaffected by short-term

609 fragmentation. Oikos 105: 359-367.

610

Jongman, R.H.G., M. Külvik and I. Kristiansen. 2004. European ecological networks and greenways.

612 Landscape Urban Plan. 68: 305-319.

613

614 Kadoya, T. 2009. Assessing functional connectivity using empirical data. Popul. Ecol. 51: 5-15.

615

616 Kindlmann, P. and F. Burel. 2008. Connectivity measures: a review. Landscape Ecol. 23: 879-890.

617

618 Laitila, J. and A. Moilanen. 2013. Approximating the dispersal of multi-species ecological entities such

619 as communities, ecosystems or habitat types. Ecol. Model. 259: 24-29.

620

621 Lennon, J.J., P. Koleff, J.J.D. Greenwood and K.J. Gaston. 2001. The geographical structure of British

622 bird distributions: diversity, spatial turnover and scale. J. Anim. Ecol. 70: 966-979.

623

624 Ludwig, M., H. Schlinkert, A. Holzschuh, C. Fischer, C. Scherber, A. Trnka, T. Tscharntke and P. Batáry.

625 2012. Landscape-moderated bird nest predation in hedges and forest edges. Acta Oecol. 45: 50-56.

626

627 Magurran, A. E. 2009. Measuring Biological Diversity. Oxford: Blackwell.

628

629 McRae, B.H. 2006. Isolation by resistance. Evolution 60: 1551-1561. 
631 Moilanen, A. 2011. On the limitations of graph-theoretic connectivity in spatial ecology and conservation.

632 J. Appl. Ecol. 48: 1543-1547.

633

634 Muratet, A., R. Lorrillière, P. Clergeau and C. Fontaine. 2013. Evaluation of landscape connectivity at community level using satellite-derived NDVI. Landscape Ecol. 28: 95-105.

636

637

Ockinger, E. and H.G. Smith. 2008. Do corridors promote dispersal in grassland butterflies and other insects? Landscape Ecol. 23: 27-40.

639

640 Oksanen, J., F. G. Blanchet, R. Kindt, P. Legendre, P.R. Minchin, R.B. O'Hara, G.L. Simpson, P.

641 Solymos, M.H.H. Stevens and H. Wagner. 2013. vegan: Community Ecology Package. R package

642 version 2.0-10. http://CRAN.R-project.org/package=vegan

643

644 Paradis, E., S.R. Baillie, W.J. Sutherland and R.D. Gregory. 1998 Patterns of natal and breeding dispersal 645 in birds. J. Anim. Ecol. 67: 518-536.

646

647 Paradis E., J. Claude and K. Strimmer. 2004. APE: analyses of phylogenetics and evolution in R

648 language. Bioinformatics 20: 289-290.

649

650 Pascual-Hortal, L. and S. Saura. 2007. Impact of spatial scale on the identification of critical habitat

651 patches for the maintenance of landscape connectivity. Landscape Urban Plan. 83: 176-186.

652

653 Peach, W.J., S.R. Baillie and D.E. Balmer. 1998. Long-term changes in the abundance of passerines in

654 Britain and Ireland as measured by constant effort mist-netting. Bird Study 45: 257-275.

655

656 Price, B., C.A. McAlpine, A.S. Kutt, S.R. Phinn, D.V. Pullar and J.A. Ludwig. 2009. Continuum or

657 discrete patch landscape models for savanna birds? Towards a pluralistic approach. Ecography 32: 745-

658 756. 
660 Ralph, C.J., G.R. Geupel, P. Pyle, T.E. Martin and D.F. DeSante. 1993. Handbook of field methods for 661 monitoring landbirds. Gen. Tech. Rep. PSW-GTR-144. Albany, CA: Pacific Southwest Research Station, 662 Forest Service, U.S. Department of Agriculture.

663

664 Rayfield, B., M.J. Fortin and A. Fall. 2010. The sensitivity of least-cost habitat graphs to relative cost 665 surface values. Landscape Ecol. 25: 519-532.

666

667 Rösch, V., T. Tscharntke, C. Scherber and P. Batáry. 2013. Landscape composition, connectivity and fragment size drive effects of grassland fragmentation on insect communities. J. Appl. Ecol. 50: 387-394.

669

670

Sala, O.E., F.S. Chapin III, J.J. Armesto, E. Berlow, J. Bloomfield, R. Dirzo, E. Huber-Sanwald, L.F. M.T. Sykes, B.H. Walker, M. Walker and D.H. Wall. 2000. Global biodiversity scenarios for the year 2100. Science 287: 1770-1774.

674

675

Sauer, J.R., J.E. Hines and J. Fallon. 2004. The North American Breeding Bird Survey, results and

676 analysis 1966-2003. Version 2004.1. Laurel, MD: USGS Patuxent Wildlife Research Center.

677

678

Saura, S. and L. Pascual-Hortal. 2007. A new habitat availability index to integrate connectivity in landscape conservation planning: comparison with existing indices and application to a case study. Landscape Urban Plan. 83: 91-103

681

682 Saura, S. and L. Rubio. 2010. A common currency for the different ways in which patches and links can 683 contribute to habitat availability and connectivity in the landscape. Ecography 33: 523-537.

684

685 Saura, S. and J. Torné. 2009. Conefor Sensinode 2.2: A software package for quantifying the importance 686 of habitat patches for landscape connectivity. Environ. Modell. Softw. 24: 135-139.

687 
Smith, A., N. Koper, C.M. Francis and L. Fahrig. 2009. Confronting collinearity: comparing methods for

694 Sutherland, G.D., A.S. Harestad, K. Price and K.P. Lertzman. 2000. Scaling of natal dispersal distances in terrestrial birds and mammals. Conserv. Ecol. 4 (1), 16, http://www.consecol.org/vol4/iss1/art16.

696

697

Taylor, P.D., L. Fahrig, K. Henein and G. Merriam. 1993. Connectivity is a vital element of landscape

698 structure. Oikos 68: 571-573.

699 role of habitat selection. Biol. Conserv. 71: 61-67.

706 $1205-1218$.

709

710 Vannier, C. 2012. Analyse spatiale de structures paysagères en contexte agricole bocage. Cybergeo:

711 European Journal of Geography, Environment, Nature, Landscape: 607. Available at

712 http://cybergeo.revues.org/25354?lang=en.

714 Venables, W.N. and B.D. Ripley. 2002. Modern Applied Statistics with S. Fourth Edition. Springer, New York. ISBN 0-387-95457-0.

716 
717 Verboom, J., A. Schotman, P. Opdam and J.A. J. Metz. 1991. European Nuthatch Metapopulations in a

718 Fragmented Agricultural Landscape. Oikos 61: 149-156.

719

720 Watts, K., A.E. Eycott, P. Handley, D. Ray, J.W. Humphrey and C.P. Quin. 2010. Targeting and

721 evaluating biodiversity conservation action within fragmented landscapes: an approach based on generic

722 focal species and least-cost networks. Landscape Ecol. 25: 1305-1318.

723

724 Wolda, H. 1981. Similarity indices, sample size and diversity. Oecologia 50: 296-302. 


\section{TABLES}

Table 1. Friction values used to model landscape matrix permeability based on the vertical structure of the maximum friction threshold of 50 .

\begin{tabular}{llr}
\hline & Land cover type & Friction value \\
\hline \multirow{5}{*}{ Decreasing permeability } & Woodlands and forests $\geq 1$ ha & 1 \\
& Hedgerows and woodlands < 1 ha & 2.57 \\
& Semi-natural and managed grasslands & 6.84 \\
& Crops & 18.4 \\
& Water bodies and watercourses & 18.4 \\
& Artificial lands (urban areas and roads) & 50 \\
\hline
\end{tabular}


770

771

772

773

774

775

776

777

778

779

Table 2. Summary statistics of the response variables characterizing woodland bird communities, the

connectivity values according to the factors considered for connectivity assessment, and the other factors describing the sampled woodlands $(n=25)$. min: minimum value, max: maximum value, std: standard deviation. In order of appearance, the abbreviation of the connectivity metric indicates the type of graph computed (Complete and minimum planar graph, $\mathrm{C}$ and mpg, respectively), the consideration or not of the matrix heterogeneity [i.e., effective (Ef) or Euclidean (Eu) distances among forests and woodlands],

the spatial resolution of the friction surface $(2$ and $10 \mathrm{~m})$ and the spatial extent considered around the study area where the woodlands were sampled ( 3 and $5 \mathrm{~km}) . *$ Information is not available for two woodlands.

\begin{tabular}{llrrrr}
\hline & & min & \multicolumn{1}{c}{ max } & mean & \multicolumn{1}{l}{ Std } \\
\hline Descriptors of woodland bird & Species richness & 12.00 & 21.00 & 15.48 & 2.35 \\
community & Abundance & 18.00 & 32.50 & 25.14 & 3.90 \\
& Composition similarity & 0.73 & 0.88 & 0.82 & 0.05 \\
& Proportional similarity & 0.74 & 0.86 & 0.82 & 0.03 \\
\hline & CEf2m3km & 0.52 & 0.67 & 0.60 & 0.04 \\
& mpgEf2m3km & 0.52 & 0.68 & 0.60 & 0.04 \\
& CEf10m3km & 0.53 & 0.68 & 0.61 & 0.04 \\
& mpgEf10m3km & 0.53 & 0.69 & 0.61 & 0.04 \\
& CEu2m3km & 0.39 & 0.86 & 0.64 & 0.11 \\
& mpgEu2m3km & 0.39 & 0.86 & 0.64 & 0.11 \\
& CEu10m3km & 0.38 & 0.87 & 0.64 & 0.12 \\
& mpgEu10m3km & 0.38 & 0.87 & 0.64 & 0.12 \\
& CEf10m5km & 0.44 & 0.56 & 0.51 & 0.04 \\
& mpgEf10m5km & 0.44 & 0.56 & 0.51 & 0.04 \\
& CEu10m5km & 0.32 & 0.73 & 0.55 & 0.09 \\
& mpgEu10m5km & 0.32 & 0.73 & 0.55 & 0.10 \\
\hline Habitat factors & Woodland size (ha) & 1.13 & 8.01 & 2.97 & 1.81 \\
& Age (years)* & 10.00 & 150.00 & 83.04 & 51.30 \\
& Tree species richness & 3.00 & 14.00 & 10.04 & 2.73 \\
& Averaged canopy cover $(\%)$ & 38.33 & 90.83 & 64.60 & 15.26 \\
\hline
\end{tabular}


Table 3. Significant models of the factors behind woodland bird proportional similarity and abundance.

798 A backward step-wise variable selection was performed for each model in which woodland size was

799 always retained to avoid bias due to the different size of the sampled woodlands ( $1-8$ ha). In the case of

800 the proportional similarity model, the independent variables were standardised to compare their respective

801 magnitude of influence. See abbreviations regarding the connectivity metric in Fig. $3 . * p \leq 0.05$, **

$802 \mathrm{p} \leq 0.01$ and $* * * \mathrm{p} \leq 0.001$. Absence of significant spatial autocorrelation of model residuals was checked

803 through Moran's $I(p>0.05)$.

\begin{tabular}{|c|c|c|c|c|c|}
\hline Response variable & Parameter & Intercept and Estimate & $\mathrm{AICc}$ & adjusted- $R^{2}$ & Model $p$ \\
\hline \multirow[t]{3}{*}{ Proportional similarity } & & $0.817 * * *$ & -105.28 & 0.20 & 0.03 \\
\hline & woodland size & $0.013 *$ & & & \\
\hline & $\mathrm{CEf} 2 \mathrm{~m} 3 \mathrm{~km}$ & $-0.013^{*}$ & & & \\
\hline \multirow[t]{3}{*}{ Proportional similarity } & & $0.817 * * *$ & -105.26 & 0.20 & 0.03 \\
\hline & woodland size & $0.013^{*}$ & & & \\
\hline & $\operatorname{mpgEf} 2 \mathrm{~m} 3 \mathrm{~km}$ & $-0.013^{*}$ & & & \\
\hline \multirow[t]{3}{*}{ Proportional similarity } & & $0.817 * * *$ & -105.08 & 0.20 & 0.03 \\
\hline & woodland size & $0.013 *$ & & & \\
\hline & CEf10m5km & $-0.013 *$ & & & \\
\hline \multirow[t]{3}{*}{ Proportional similarity } & & $0.817 * * *$ & -104.97 & 0.19 & 0.04 \\
\hline & woodland size & $0.013 *$ & & & \\
\hline & CEf10m3km & $-0.013^{*}$ & & & \\
\hline \multirow[t]{3}{*}{ Proportional similarity } & & $0.817 * * *$ & -104.93 & 0.19 & 0.04 \\
\hline & woodland size & $0.013 *$ & & & \\
\hline & $\mathrm{mpgEf} 10 \mathrm{~m} 5 \mathrm{~km}$ & $-0.012 *$ & & & \\
\hline \multirow[t]{3}{*}{ Proportional similarity } & & $0.817 * * *$ & -104.85 & 0.19 & 0.04 \\
\hline & woodland size & $0.013 *$ & & & \\
\hline & mpgEf $10 \mathrm{~m} 3 \mathrm{~km}$ & $-0.012 *$ & & & \\
\hline \multirow[t]{2}{*}{ Proportional similarity } & & $0.817 * * *$ & -102.41 & 0.06 & 0.12 \\
\hline & woodland size & $0.009 *$ & & & \\
\hline \multirow[t]{2}{*}{ Abundance } & & $22.21 * * *$ & & 0.18 & 0.02 \\
\hline & woodland size & $0.987 *$ & & & \\
\hline
\end{tabular}




\section{FIGURE CAPTIONS}

805 Figure 1. Geographic location of the study area (north-east Brittany in north-west France) (left) and

806 representation of the land uses in the study area (Armorique ZA) and the sampled woodlands (dots; $n=$

807 25) within the different extents used to compute connectivity measures (right). The land uses shown

808 correspond to the categories of the friction values (see Table 1).

810 Figure 2. Increasingly ranked relative maximum abundance of the bird species pool of the woodlands in

811 the study area. Bird species occurrence in the sampled woodlands $(n=25)$ is also shown. For each species

812 recorded and all the sampled woodlands of the study area, the relative maximum abundance (\%) was

813 computed from the sum of the maximum abundance for each species during the three visits in the

814 breeding season regarding the sum of the maximum abundance for all the species. Geometric mean natal

815 dispersal $(\mathrm{km})$ according to Paradis et al. (1998) is shown in brackets when available.

816

817 Figure 3. Factors considered in the connectivity assessment through graph theory. Abbreviations in

818 brackets comprise the nomenclature of the connectivity measure and represent, in order of appearance,

819 the type of graph computed (C / mpg), the consideration or not of the matrix heterogeneity (Eu / Ef), the

820 spatial grain of the friction surface $(2 \mathrm{~m} / 10 \mathrm{~m})$ and the spatial extent considered around the study area

821 where the woodlands were sampled $(3 \mathrm{~km} / 5 \mathrm{~km})$.

823 Figure 4: Boxplot of the connectivity values according to the different factors considered to compute

824 graph-based connectivity in the 143 woodlands and forests ( $\geq 1$ ha) within the study area (the thickest

825 edge represented in Fig. 1). See abbreviations regarding the connectivity metric in Figure 3.

827 Figure 5. Response curves of the top regression model according to the AICc approach for similarity in

828 terms of proportional species composition (Table 3). Independent variables were not standardised and

829 each time the unrepresented predictor [connectivity $(\mathrm{CEF} 2 \mathrm{~m} 3 \mathrm{~km})$ above and woodland size below,

830 respectively] was set constant (mean value).

831

832 
833 Figure 1. Geographic location of the study area (north-east Brittany in north-west France) (left) and

834 representation of the land uses in the study area (Armorique ZA) and the sampled woodlands (dots; $n=$

835 25) within the different extents used to compute connectivity measures (right). The land uses shown

836 correspond to the categories of the friction values (see Table 1).

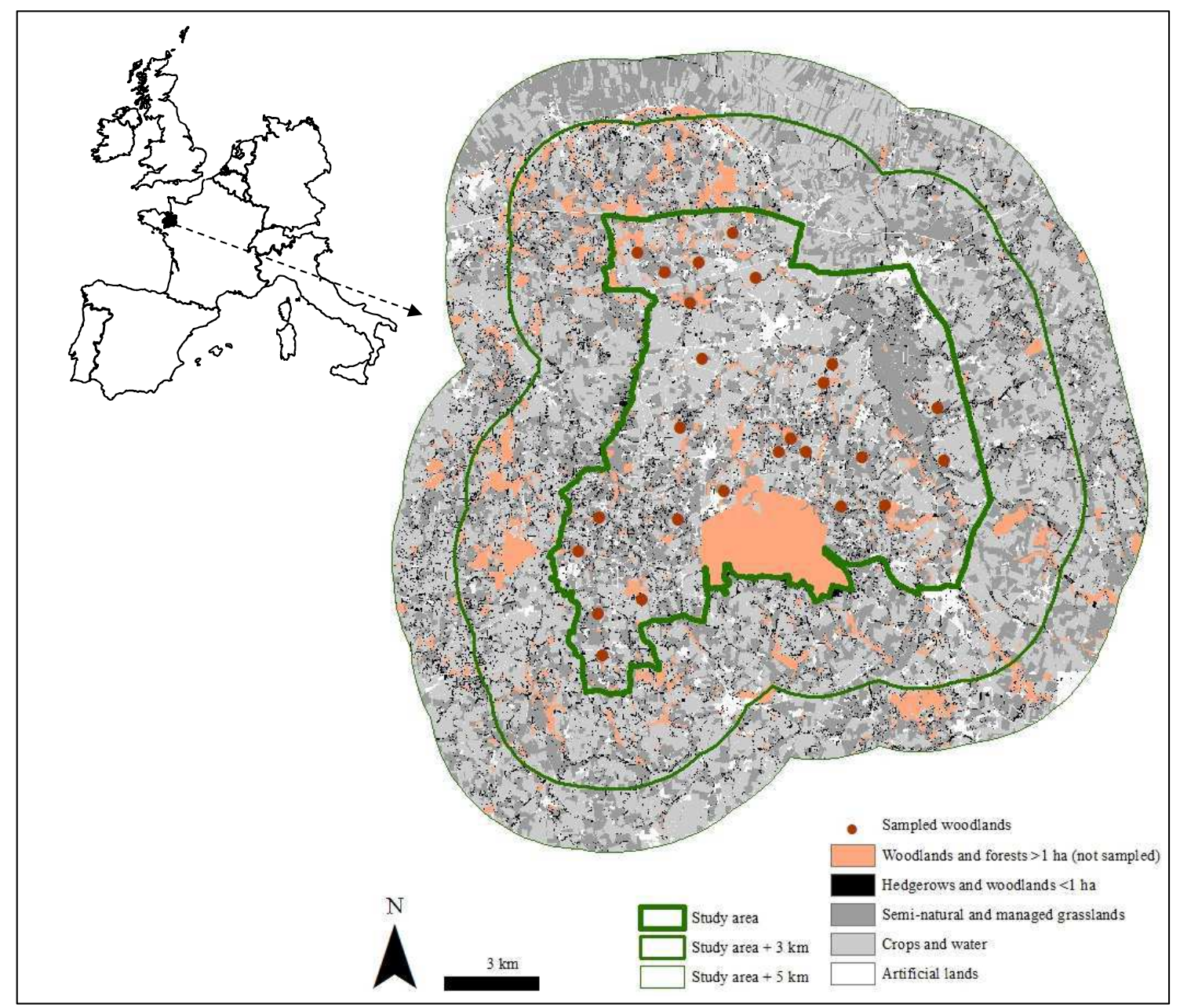


856 Figure 2. Increasingly ranked relative maximum abundance of the bird species pool of the woodlands in

857 the study area. Bird species occurrence in the sampled woodlands $(n=25)$ is also shown. For each species

858 recorded and all the sampled woodlands of the study area, the relative maximum abundance (\%) was

859 computed from the sum of the maximum abundance for each species during the three visits in the

860 breeding season regarding the sum of the maximum abundance for all the species. Geometric mean natal

861 dispersal $(\mathrm{km})$ according to Paradis et al. (1998) is shown in brackets when available.

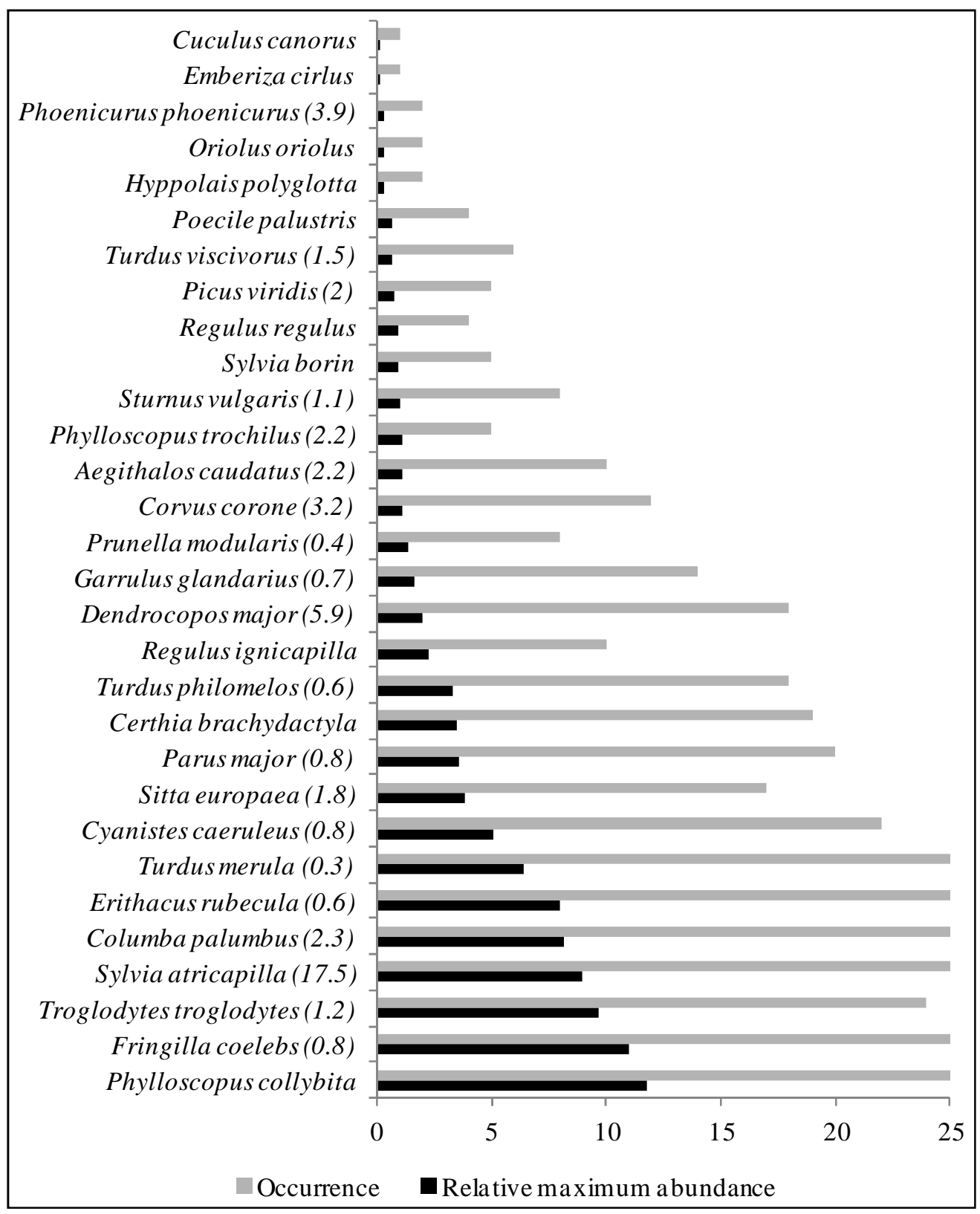


864 Figure 3. Factors considered in the connectivity assessment through graph theory. Abbreviations in brackets comprise the nomenclature of the connectivity measure and represent, in order of appearance,

866 the type of graph computed (C / mpg), the consideration or not of the matrix heterogeneity (Eu / Ef), the spatial grain of the friction surface $(2 \mathrm{~m} / 10 \mathrm{~m})$ and the spatial extent considered around the study area

868 where the woodlands were sampled $(3 \mathrm{~km} / 5 \mathrm{~km})$.

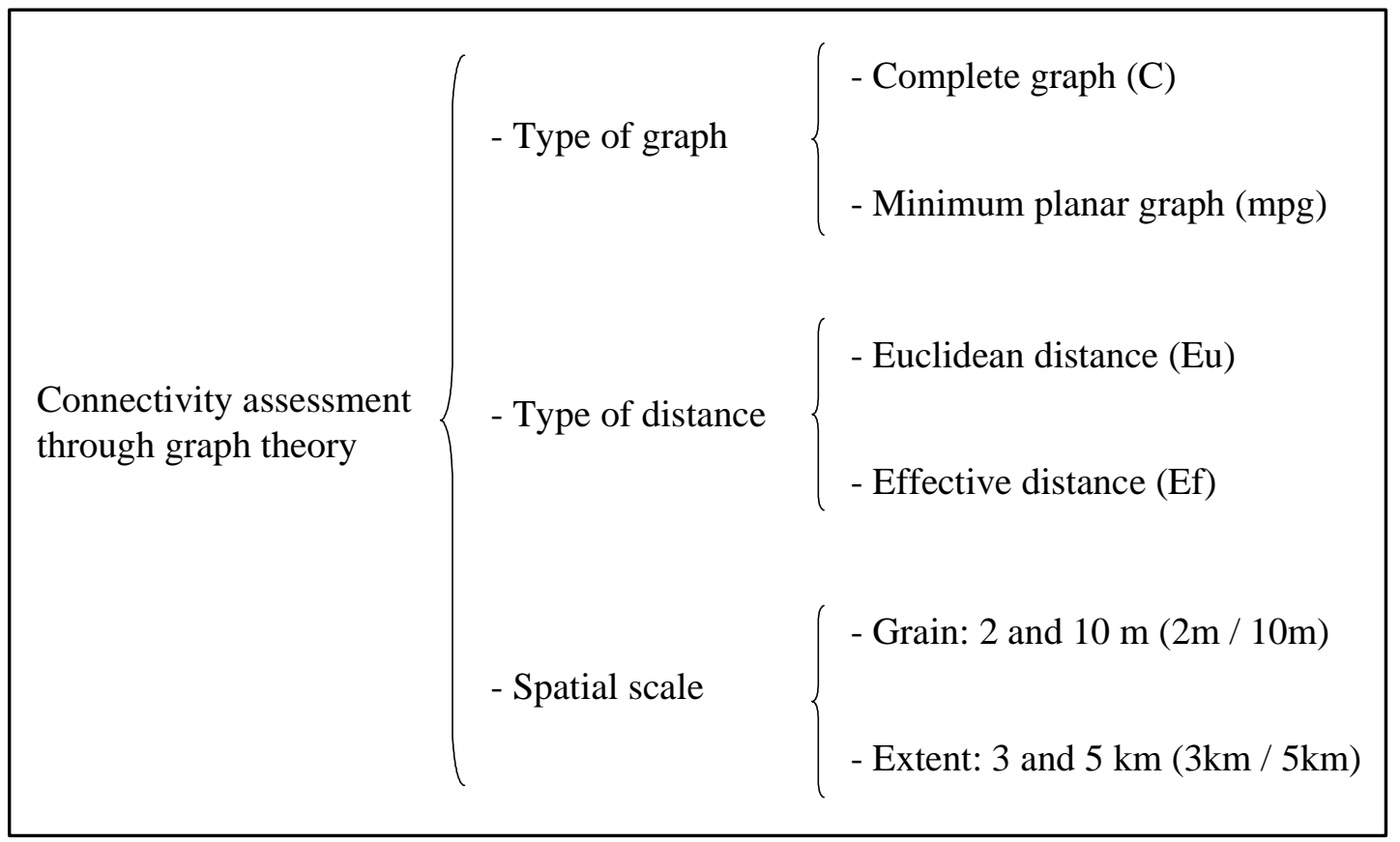


896 Figure 4: Boxplot of the connectivity values according to the different factors considered to compute

897 graph-based connectivity in the 143 woodlands and forests ( $\geq 1$ ha) within the study area (Armorique ZA,

898 corresponding to the thickest edge represented in Fig. 1). See abbreviations regarding the connectivity metric in Figure 3.
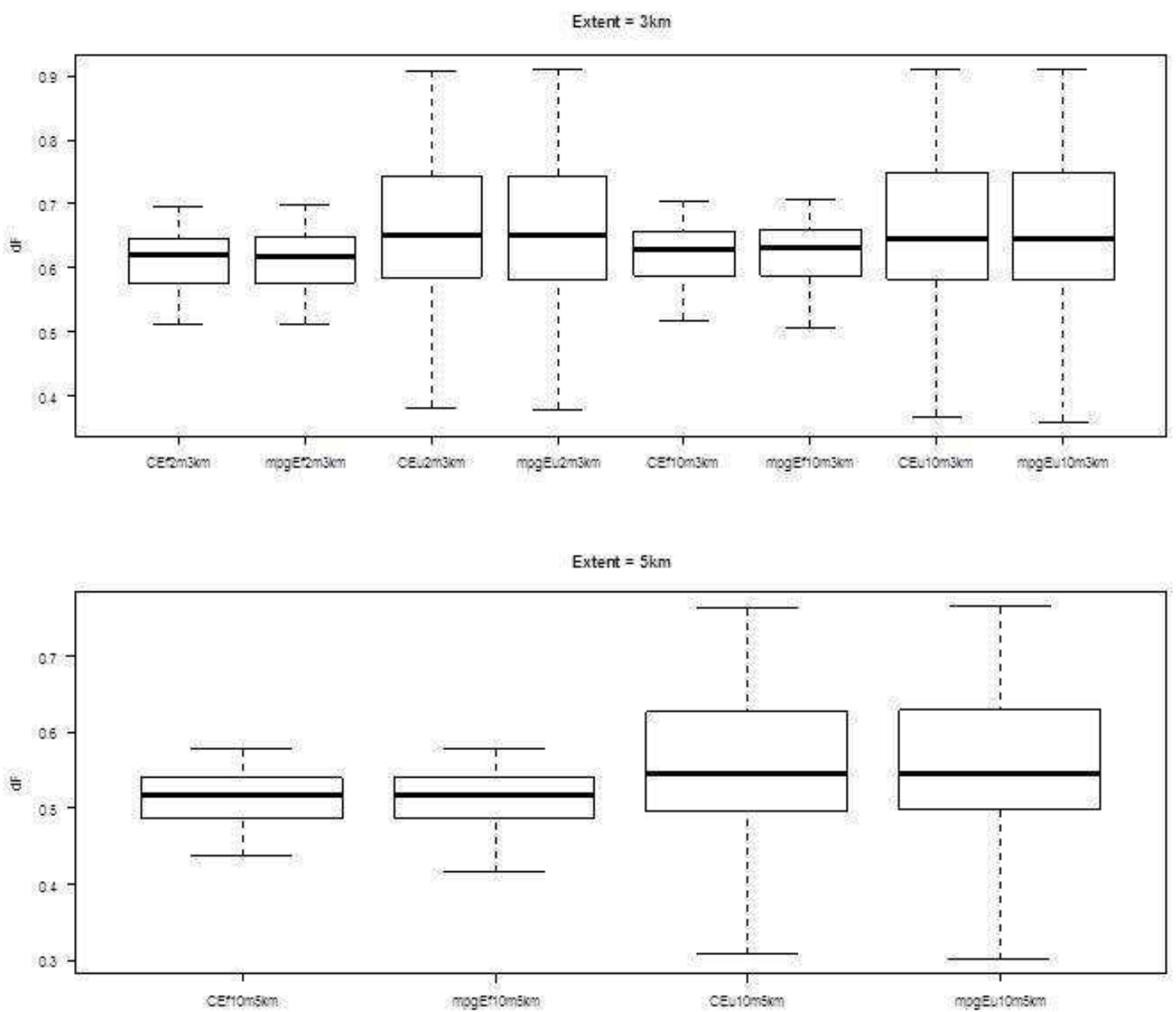

900

901

902

903

904

905

906 
907 Figure 5. Response curves of the top regression model according to the AICc approach for similarity in

908 terms of proportional species composition (Table 3). Independent variables were not standardised and

909 each time the unrepresented predictor [connectivity (CEf2 $3 \mathrm{~km})$ above and woodland size below,

910 respectively] was set constant (mean value).
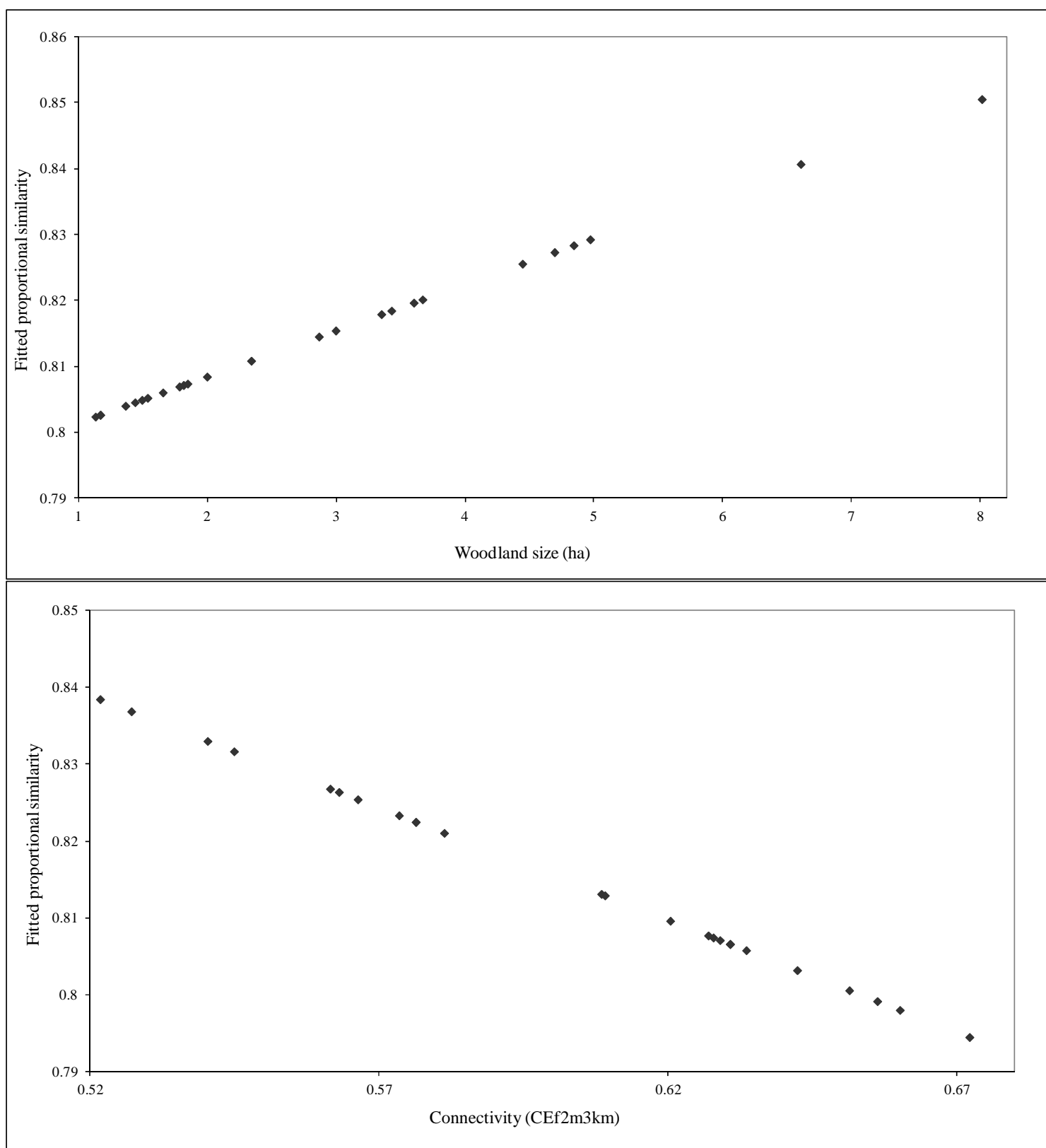